\title{
Growth and Study of ADP Crystal Doped with Acridine Orange
}

\author{
R. Nandhakumar'1, T. Radhakrishnan ${ }^{2}$ \\ ${ }^{1}$ School of Education, Srinivasa Ramanujan Centre, Shanmugha Arts, Science, Technology and Research \\ Academy, Kumbakonam, India \\ ${ }^{2}$ Department of Physics, Srinivasa Ramanujan Centre, Shanmugha Arts, Science, Technology and Research \\ Academy, Kumbakonam, India \\ Email: nandha_70@src.sastra.edu, radhakrishnan@src.sastra.edu
}

Received 12 February 2016; accepted 27 March 2016; published 30 March 2016

Copyright (C) 2016 by authors and Scientific Research Publishing Inc.

This work is licensed under the Creative Commons Attribution International License (CC BY).

http://creativecommons.org/licenses/by/4.0/

\section{(c) (i) Open Access}

\begin{abstract}
Materials with large non-linear optical properties are good candidates for applications in the fields of telecommunications, solar energy conversion, laser treatment and so on. In the present study, a crystal of Ammonium Dihydrogen Orthophosphate doped with Acridine Orange, possessing excellent nonlinear optical properties were grown by the slow solvent evaporation technique at $25^{\circ} \mathrm{C}$ using a constant temperature bath. Ammonium dihydrogen orthophosphate doped with Acridine Orange were synthesized in a large quantity via solution growth method using aqueous mixtures of Ammonium Dihydrogen Orthophosphate and Acridine Orange. The morphological characteristics were studied by field emission scanning electron microscopy which revealed that the synthesized product possesses needle shaped microstructures. The mechanical properties are studied by Vicker's micro hardness test.
\end{abstract}

\section{Keywords}

Impurities, Nucleation, Supersaturated, Growth from Solutions, Organic Compound, Non-Linear Optical Material

\section{Introduction}

Acridine orange $\mathrm{C}_{17} \mathrm{H}_{13} \mathrm{~N}_{3}$ is an organic compound and a nitrogen heterocyclic. Acridine is structurally related to Anthracene [1] [2] in which one of the central $\mathrm{CH}$ group is replaced by nitrogen. Acridine is a promising candidate of compounds of fluorescent dyads because they often exhibit strong solvate chromatic fluorescence. Previous studies indicate that the presence of Hetero Aromatics in conjugated organic acceptor dyads is highly 
beneficial for the observation of large non-linear optical properties [1]. Acridine Orange, due to its meta chromic properties, is commonly used in fluorescence microscopy and flow cytometry analysis of cellular physiology and cell cycle status, including the fluorescent microscopic examination of microorganisms. Ammonium Dihydrogen Orthophosphate is widely used in second, third and fourth harmonic generator, frequency conversion, Q switch and quantum electronics as well as electro-optical and acousto-optical applications [2]-[4]. It is a selective metachromatic stain, useful for cell cycle determination. Ammonium dihydrogen orthophosphate $\mathrm{NH}_{4} \mathrm{H}_{2} \mathrm{PO}_{4}$ is a well known non-linear optical material which also has many Ferro electric and Anti Ferro electric properties [5] [6]. They are still widely used as non-linear optic devices and electro optic materials. It is known that very little amount of additives can strongly suppress the metal ion impurities and promote crystal quality [7]. Acridine orange as additives [8] in ADP crystals gives appreciable change in optical, thermal, dielectric and mechanical behaviours [9]. The effect of additives depends on the additive concentration, super saturation, temperature and $\mathrm{pH}$. The growth promoting effect in ADP is observed in the presence of Acridine orange. For higher concentration of impurities, the lattice distortion is less [10]. ADP is widely used in second, third and fourth harmonic generators. The behavior of these crystals in the radiation field includes the formation of the optical wavelength in these crystals. By slow solvent evaporation technique, ADP single crystal with Acridine Orange as impurity in very small molar ratios (1:0.005, 1:0.010, 1:0.015, 1:0.020) were grown and optical, thermal and mechanical properties were studied.

\section{Experimental Set-Up}

Crystal growth plays a vital role in the development of many solid state devices for technological applications [11]. In the recent past, there have been extensive effort to develop new inorganic, organic and semi organic nonlinear optical crystals. This paper, describes our efforts of growing ADP with Acridine orange as impurity. Crystallization from the solution is an important process and the driving force for crystallization is the degree of super saturation which has been commonly expressed as the difference in concentration between the supersaturated and saturated solutions [12]. Slow solvent evaporation technique has been widely used to grow several types of crystals at ambient temperature. Samples of $\mathrm{NH}_{4} \mathrm{H}_{2} \mathrm{PO}_{4}$ and Acridine orange along with deionized water were used for the growth of single crystals by slow solvent evaporation method [13]-[15]. ADP was added with Acridine orange with different molar ratios (1:0.005, 1:0.010, 1:0.015, 1:0.020). Single crystals of ADP doped with Acridine Orange were grown by slow cooling technique in constant temperature bath at an accuracy of $+0.01^{\circ} \mathrm{C}$. Crystals grown by slow evaporation solution growth was ensured with high crystalline perfection [13]. Before stating the growth process the material was purified by repeated recrystallization process by using deionized water as the solvent. Then the recrystallized salt was dried and made in to a powder for further growth process. A concentrated solution was prepared and then the solution was stirred continuously and warmed up slightly in order to complete the chemical reaction using a magnetic stirrer attached with hot plate [16] [17]. Then the solution was filtered and covered with a plastic sheet with holes for controlled evaporation. After a period of three weeks, highly transparent optical good quality single crystals have been harvested from the mother solution. These materials possesses large non linearity, high resistance laser induced damage and low angular sensitivity [18]-[20] [23]. The grown single crystal was subjected to single crystal X ray diffraction studies and the lattice parameters were obtained.

\section{Results and Discussion}

\subsection{Crystal Growth}

Before conducting the actual crystal growth experiments, solubility experiments [15] [21] [22] were carried out for the following solvents; deionized water, acetone, methanol and xylene at room temperature. According to the solubility data, deionized water was taken as solvent. $350 \mathrm{ml}$ saturated solution of ADP was prepared and 50ml of solution was transferred to conventional growth vessels (beaker) for collecting the seed crystal by slow solvent evaporation technique. Saturated solutions of Acridine orange were prepared and added with the saturated solution of ADP in the molar ratio of 1:0.005. Based on the quality of the grown crystals, suitable seed crystal having a microscopic size was selected for single crystal growth with specific orientation. Based on the observations related to induction period, growth rate and the solvent properties, deionized water was selected as the solvent for conducting the single crystal growth experiment with specific orientation. Prior to growth, care has 
been taken to avoid any contamination from the growth vessel which can lead to spurious nucleation. Also special care was taken for the preparation of the solution. The seed crystal was chemically polished and a specific orientation was selected. Once the system attained equilibrium, the growth was initiated with a suitable temperature provided by the ring heater at the top of the super saturated solution. The effective zone width of the solution and the maximum temperature of the ring heater determine the effective evaporation rate of the supersaturated solution. Nucleation occurred within two days and crystals reached a large size in 10 days. Grown crystals were stable, Orange coloured and needle shaped [23]. Relatively large crystals up to $1 \times 1 \times 0.5 \mathrm{~cm}^{3}$ were obtained as shown in Figure 1.

\subsection{Micro Hardness}

Suitably cut and polished samples were subjected to micro hardness test. Hardness is a measure of the resistance of a material against lattice destruction or the resistance to permanent deformation or damage. The micro indentation test is a useful method for studying the nature of plastic flow and influence on the deformation of the material. Micro hardness measurements on single crystals using the conventional pyramidal indenters will be influenced by the basic anisotropic properties of the crystal. In the study of hardness, a sample of ADP crystal doped with Acridine orange was subjected to relatively high pressure within a localized area. In the present work Vicker's pyramid indenter has been used to study the micro hardness of a sample of ADP crystal doped with Acridine orange. The hardness of the crystal is calculated using the relation $\mathrm{Hv}=1.8544 \times\left(\mathrm{p} / \mathrm{d}^{2}\right)$.The load varying from 5 gms to 25 gms was applied over a fixed interval of time. The intended impressions were rhombic. Using micrometer eye piece diagonal lengths of the impressions obtained from various loads were measured. With each load, several trials of indentation marks were calculated. The values of diagonal length of indenter impressions and micro hardness numbers related to ADP doped with Acridine orange were calculated for different loads, shown in the Table 1. Table 2 shows the values of diagonal length of indenter impressions and micro hardness numbers, calculated using the pure ADP for different loads. The variation in micro hardness number is shown in the Figure 2.

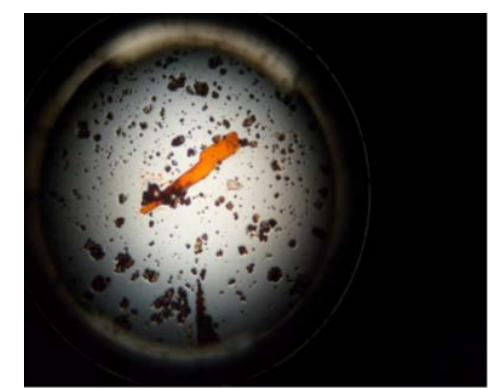

Figure 1. Structure of ADP doped with Ao.

Table 1. Calculation of microhardness of Adp doped with Ao.

\begin{tabular}{ccc}
\hline Load(p) Gms & Diagonal length of indentation (nm) & Micro hardness number $\mathrm{Hv} \mathrm{Kg} / \mathrm{mm}^{2}$ \\
\hline 10 & 11.25 & 14.65 \\
25 & 20.75 & 107.6 \\
50 & 31.25 & 94.9 \\
\hline
\end{tabular}

Table 2. Calculation of microhardness of pure ADP.

\begin{tabular}{ccc}
\hline Load(p) Gms & Diagonal length of indentation (nm) & ${\text { Micro hardness number Hv Kg/mm }{ }^{2}}$ \\
10 & 12.45 & 11.9 \\
25 & 22.65 & 90 \\
50 & 42.05 & 52 \\
\hline
\end{tabular}




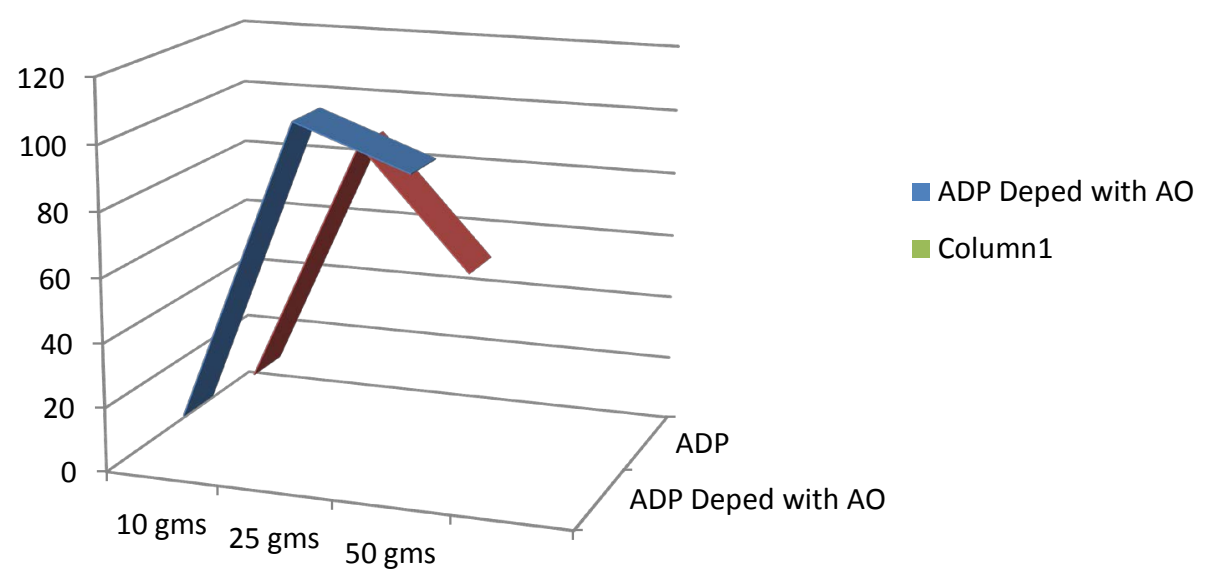

Figure 2. Graph indicating variation in microhardness.

\section{Conclusion}

Organic compound Acridine orange was successfully doped with ADP crystal and it was found that these additives can affect the nucleation of ADP from aqueous solutions. ADP was added with Acridine orange with different molar ratios (1:0.005, 1:0.010, 1:0.015, 1:0.020). Single crystals of ADP doped with Acridine Orange were grown by slow cooling technique in constant temperature bath at an accuracy of $+0.01^{\circ} \mathrm{C}$. Micro indentation test, conducted using Vicker's test, reveals that the hardness of a ADP crystal increases when ADP was added with Acridine orange.

\section{References}

[1] Maneria, S., Ehrensperger, M., Bosshard, C. and Gilnter, P. (2002) Organic Thin Film Crystal Growth for Nonlinear Optics: Present Methods and Exploratory Developments. Comptes Rendus Physique, 3, 449-462. http://dx.doi.org/10.1016/S1631-0705(02)01338-5

[2] Lakshmana Perumal, C.K., Arul Chakkaravarthy, A., Balamurugan, N., Santhana Raghavan, P. and Ramasamy, P. (2002) Synthesis, Crystal Growth and Characterisation of Novel NLO Material: 4-Hydroxy Benzaldehyde-N-Methyl4-Stilbazolium Tosylate. Journal of Crystal Growth, 265, 260. http://dx.doi.org/10.1016/j.jcrysgro.2003.12.011

[3] Lakshmana Perumal C.K., Arul Chakkaravarthy A., Rajesh N.P., Santhana Raghavan P., Huang V.C., Ichimura. M. and Ramasamy, P. (2002) Synthesis, Crystal Growth and FTIR, NMR, SHG Studies of 4-Methoxy Benzaldehyde-NMethyl-4-Stilbazolium Tosylate (MBST). Journal of Crystal Growth, 240, 212. http://dx.doi.org/10.1016/S0022-0248(02)00857-6

[4] Abdel-Kader, A. (1991) Journal of Materials Science: Materials in Electronics, 2, 204-208.

[5] Marder, S.R., Perry, J.W. and Schacfer, W.P. (1989) Synthesis of Organic Salts with Large Second-Order Optical Nonlinearities, Science, 245, 626. http://dx.doi.org/10.1126/science.245.4918.626

[6] Marder, S.R., Perry, J.W. and Yakymyshyn, C.P. (1994) Chem.mat 6.

[7] Umezawa, R., Tsuji, K., Okada, S., Olkawa, H., Matusuda, R. and Nakanishi, R. (2002) Molecular Design on Substituted DAST Derivatives for Second-Order Nonlinear Optics. Optical Materials, 21, 75. http://dx.doi.org/10.1016/S0925-3467(02)00116-7

[8] Lal, K. and Bhaghavannarayana, G. (1989) A High-Resolution Diffuse X-Ray Scattering Study of Defects in Dislocation-Free Silicon Crystals Grown by the Float-Zone Method and Comparison with Czochralski-Grown Crystals. Journal of Applied Crystallography, 22, 209. http://dx.doi.org/10.1107/S0021889888014062

[9] Bhaghavannarayana, G., Anandamurthy, R.V., Budakoti, G.C., Kumar, B. and Bartwal, K.S. (1989) A Study of the Effect of Annealing on Fe-Doped LiNbO3 by HRXRD, XRT and FT-IR. Journal of Applied Crystallography, 38, 768. http://dx.doi.org/10.1107/S0021889805023745

[10] Bernerman, B.W. and Cole, H. (1964) Dynamical Diffraction of X Rays by Perfect Crystals. Reviews of Modern Physics, 36, 681 .

[11] Kiryk, I.V., Mareinrak, B. and Mefleh, A. (2001) Journal of Physics D, 341.

[12] Sasaki, T. and Yokotani, A. (1990) Journal of Crystal Growth, 99820-99826. 
[13] Zhang, H., Batra, A.K. and Lal, R.B. (1994) Growth of Large Methyl-(2,4-dinitrophenyl)-Aminopropanoate: 2-Methyl4-Nitroaniline Crystals for Nonlinear Optical Applications. Journal of Crystal Growth, 137, 141-144. http://dx.doi.org/10.1107/S0021889805023745

[14] Gallagher, H.G., Vrcelj, R.M. and Sheerwood, J.N. (2003) The Crystal Growth and Perfection of 2,4,6-Trinitrotoluene. Journal of Crystal Growth, 250, 486-498.

[15] Martin Britto Dhas, S.A., Suresh, M., Bhaghavannarayana, G. and Natarajan, S. (2007) Growth and Characterization of l-Tartaric Acid, an NLO Material. Journal of Crystal Growth, 309, 48-52.

[16] Zernike, F. and Midwinter, J.E. (1973) Applied Nonlinear Optics, John Wiley \& Sons Inc.

[17] Davey, R.J. and Mullin, J.W. (1984) Krist. Technol, 11, 22.

[18] Levina, M. and Belyustin, A.V. (1980) Soviet Physics, Crystallography, 25, 209.

[19] Nagalingam, S., Vasudevan, S. and Ramasamy, P. (1981) Effect of Impurities on the Nucleation of ADP from Aqueous Solution. Crystal Research and Technology, 16, 647.

[20] Ramesh, R. and Mahadevan, C. (1998) Nucleation Studies in Supersaturated Aqueous Solutions of $\left(\mathrm{NH}_{4}\right) \mathrm{H}_{2} \mathrm{PO}_{4} \mathrm{Doped}$ with $\left(\mathrm{NH}_{4}\right)_{2} \mathrm{C}_{2} \mathrm{O}_{4} \cdot \mathrm{H}_{2} \mathrm{O}$. Bulletin of Materials Science, 21, 287.

[21] Lines, M.E. and Glass, A.M. (1977) Principles and Applications of Ferroelectrics and Related Materials. Clarendon Press, Oxford.

[22] Parsonage, N.G. and Staveley, L.A.K. (1978) Disorder in Crystals. Clarendon Press, London.

[23] Wyckoff, R.W.G. (1960) Cryst. Structure. 2nd Edition, Interscienece, New York, 160. 